\title{
Characteristics of women infected with human papillomavirus in a tertiary hospital in Beijing China, 2014-2018
}

Liang Ma ${ }^{1}$, Jieping Lei ${ }^{2,3,4}$, Li Ma ${ }^{5}$, Xiao Cong ${ }^{1}$, Na Wang ${ }^{6}$, Hui Yang ${ }^{1}$, Qian Liu' ${ }^{1}$ Yang Yu ${ }^{1}$ and Yongtong Cao ${ }^{1 *}$

\begin{abstract}
Background: Human papillomavirus (HPV) infection is the main cause of precancerous lesions and cervical cancer in women. In order to determine the epidemiological characteristics as well as the relationship between the HPV genotype and cytology test results among women in Beijing, China, we retrospectively collected and analyzed the data from a tertiary hospital in Beijing, China.

Methods: A total of 21,239 women visited the China-Japan Friendship Hospital between 2014 and 2018 and their cervical exfoliations were collected. Thirteen HPV subtypes (16, 18, 31, 33, 35, 39, 45, 51, 52, 56, 58, 59 and 68) were examined and ThinPrep cytological test (TCT) was performed.

Results: Among all cases, 4473 (21.06\%) women were infected with HPV. HPV52 (4.64\%), HPV16 (4.44\%) and HPV58 (4.28\%) had higher prevalence. Single-type infection (77.26\%) was more common than multiple-type infection (22.74\%). Single-type infection was more frequently seen in women aged 50-60 years (17.17\%), and multiple-type infection was more common in those aged <30 years (7.88\%). Significant differences in secular trends from 2014 to 2018 were observed for subtypes HPV39, 51, 52 and 58. HPV positive rates of women aged $<30$ and 30-40 years changed significantly along with the time period, and the TCT positive rates of women aged 30-40, 40-50, 50-60 and > 60 years also showed significant differences from 2014 to 2018. In addition, 1746 (8.22\%) women were TCT positive, of whom, 858 (4.04\%), 561 (2.64\%) and 327 (1.54\%) had atypical squamous cells (ASCs), low-grade squamous intraepithelial lesions (LSILs) and high-grade squamous intraepithelial lesions (HSILs), respectively. Among four types of cytological lesions, the HPV infection rates were $16.76,66.08,63.99$ and $85.32 \%$ in those negative for intraepithelial lesions or malignancy (NILM), ASC, LSIL and HSIL, respectively.
\end{abstract}

Conclusions: HPV52, 16 and 58 are the most common infection subtypes in this study and among four types of cytological lesions, HSILs has the highest HPV prevalence. Significant differences in secular trends are observed for different subtypes in recent 5 years. The results on HPV genotype-specific prevalence should be considered when the HPV vaccine program is implemented in Beijing area.

Keywords: Human papillomavirus, Genotype, ThinPrep cytological test

\footnotetext{
* Correspondence: caoyongtong92@sina.com

${ }^{1}$ Clinical Laboratory, China-Japan Friendship Hospital, Beijing, People's

Republic of China

Full list of author information is available at the end of the article
}

(c) The Author(s). 2019 Open Access This article is distributed under the terms of the Creative Commons Attribution 4.0 International License (http://creativecommons.org/licenses/by/4.0/), which permits unrestricted use, distribution, and reproduction in any medium, provided you give appropriate credit to the original author(s) and the source, provide a link to the Creative Commons license, and indicate if changes were made. The Creative Commons Public Domain Dedication waiver (http://creativecommons.org/publicdomain/zero/1.0/) applies to the data made available in this article, unless otherwise stated. 


\section{Background}

Cervical cancer is the fourth most commonly encountered malignancy among women worldwide [1]. It is estimated that $85 \%$ of the 528,000 new cases and $87 \%$ of the 266,000 deaths from cervical cancer occurred in developing countries in 2012 [2]. In China, cervical cancer ranks seventh and ninth in cancer prevalence and mortality in women, respectively [3]. Persistent human papillomavirus (HPV) infection, especially high-risk HPV (HR-HPV) infection, is the main cause of precancerous lesions and cervical cancer $[4,5]$. HPV is a small double-stranded, circular DNA virus that belongs to the family Papillomavirus [6]. There are $200 \mathrm{HPV}$ genotypes that have been identified until now, and HR-HPVs are closely associated with cervical and anogenital tract cancers $[7,8]$.

HPV prevalence and genotype distribution differ geographically, and also between rural and urban women [8-11]. Epidemiological characteristics of HPV infection may also alter with population shift and habit changes. Understanding the characteristics is important and necessary to develop the HPV-based cervical cancer screening program and vaccine-based HPV prevention strategies.

Early-stage detection or diagnosis plays an important role in the prevention and treatment of cervical cancer. During recent years, with the development of cervical cancer screening programs, as well as the application of ThinPrep cytological test (TCT), the detection rate of cervical lesions has improved. HPV testing has been shown to be a reasonable option and widely used in the screening of cervical precancerous diseases [12]. HPV testing alone has also been developed as the primary screening modality in several countries [13]. However, HPV testing is too sensitive to reflect cervical lesions, and HPV can be eliminated by the immune system before causing cervical lesions. Therefore, HPV testing shows high negative predictive value (NPV) and poor positive predictive value (PPV), especially in women aged $<30$ years with high HPV infection rate [14, 15]. Furthermore, HPV testing may fail to detect cervical diseases that could be diagnosed by other methods. For instance, TCT could improve the screening efficiency of cervical cytology and provide a better medium for cervical cells [16]. The experience in the US and Europe showed that cytological screening on its own or combined with HPV testing decreased the incidence rate of cervical cancer [17]. The American Cancer Society, the American Society for Colposcopy and Cervical Pathology, and the American Society of Clinical Pathology have suggested that the combination of cytology and HPV testing significantly increase the sensitivity of cervical cancer screening [18]. Several large studies have been conducted to compare the efficacy of cytology and HPV testing in detecting precancerous lesions and cervical cancer [19-21]. In addition, a few studies have focused on the relationship between the HPV genotype and cytology test results in China.

In this study, all participants underwent cytology testing and HPV detection on the same visit. The aim of the study was to determine the epidemiological characteristics and secular trends of HPV infection subtypes in the Beijing area. We also analyzed the relationship between HPV genotype and cytology test results. We retrospectively analyzed the data from a tertiary hospital in Beijing. The results will contribute to the data on HPV genotype-specific prevalence in the Beijing area in order to encourage implementation of an HPV vaccine program.

\section{Methods}

Patient recruitment and sample collection

The China-Japan Friendship Hospital is a tertiary hospital that provides medical care in the Beijing area. We retrospectively collected the data of 21,239 women who visited the hospital and received TCT for HPV detection between 2014 and 2018. The patients' confidentiality was protected by hiding their identities. Written informed consent was obtained from all the patients prior to their enrollment in the study. The study design adhered to the principles of the Declaration of Helsinki and was approved by the ethics committee of ChinaJapan Friendship Hospital.

\section{Cytology testing}

The samples were strictly collected during the nonmenstrual period. Cervical liquid-based cytology tests were performed by experienced cytology experts at the Department of Gynaecology \& Obstetrics. The terminology for liquid-based cytology was defined according to the Bethesda System and included negative for intraepithelial lesions or malignancy (NILM), atypical squamous cells of undetermined significance (ASC-US), low-grade squamous intraepithelial lesion (LSIL), and high grade squamous intraepithelial lesion (HSIL) [22].

\section{HPV DNA testing}

Exfoliated cervical cells were collected using a specialized cervical brush. Then, the cervical samples were stored at $4{ }^{\circ} \mathrm{C}$ in standard medium provided by Liferiver (Shanghai, China). DNA isolation and purification were performed. A Chinese State Food and Drug Administrationapproved HPV genotyping assay (Liferiver) was used to detect HPV genotypes by real-time polymerase chain reaction. This test individually detected 13 high-risk HPV subtypes, including HPV16, 18, 31, 33, 35, 39, 45, 51, 52, 56, 58, 59 and 68. Amplification was performed using a real-time polymerase chain reaction (PCR) detector, and the profile consisted of denaturation at $94{ }^{\circ} \mathrm{C}$ for 2 min following 40 cycles 
of denaturation at $93^{\circ} \mathrm{C}$ for $10 \mathrm{~s}$, annealing and elongation at $62{ }^{\circ} \mathrm{C}$ for $31 \mathrm{~s}$. Single point fluorescence was detected at $62{ }^{\circ} \mathrm{C}$. Internal quality control and External quality assessment were taken in the experiment and the results met the requirements.

\section{Statistical analysis}

Data were presented as mean \pm standard deviation or frequency and percentage for numerical or discrete variables, respectively. The $x^{2}$ test was used to determine whether significant difference existed between groups for discrete variables. The Cochran-Armitage trend test was used to determine the statistical significance of changes over years. All analyses were performed using SAS 9.4 software (Cary, NC, USA).

\section{Results}

\section{Single and multiple type HPV infections in women of} different ages

A total of 21,239 women (mean age $40.02 \pm 11.38$ years) visited the China-Japan Friendship Hospital and received cervical TCT and HPV tests between 2014 and 2018. Characteristics of HPV infection as well as HPV distribution among different age categories are shown in Table 1. Among all 21,239 cases, $4473(21.06 \%)$ were infected with HPV, which was more frequently seen in 998 (998/4046, 24.67\%) women aged < 30 years. Single-type HPV infection was more frequently seen in women aged $50-60$ years (542/3157, 17.17\%), and multiple-type HPV infection was more common in those aged < 30 years (319/ 4046, 7.88\%). And apparently, in our data single-type HPV infection (3456/4473, 77.26\%) was more common than multiple-type infection $(1017 / 4473,22.74 \%)$ $\left(\chi^{2}\right.$ test $\left.P<0.0001\right)$.

Single and multiple type infection rates in women of different HPV subtypes

Among 13 HPV subtypes examined, HPV52, 16, and 58 had the higher prevalence in all included participants, with the infection rates of $4.64,4.44$ and $4.28 \%$, respectively. The three HPV subtypes were also most commonly seen in women both with single and multiple HPV infections (Table 2).

Secular trends of different HPV subtype infection rates, and HPV and TCT infection rates of different ages from 2014 to 2018

We also investigated the temporal trends of HPV subtype infections during the research period. HPV16, 52 and 58 constantly had the higher infection rates from 2014 to 2018. Significant differences in secular trends between 2014 and 2018 were seen for subtypes of HPV39, 51, 52 and 58 (all $P<0.05$, Table 3).

We found that HPV positive rates in women aged $<30$ years and 30-40 years changed significantly along with the time period $(P$ value for trend $=0.0002$ and $<0.0001$ for women aged $<30$ years and $30-40$ years, respectively). Additionally, the TCT positive rates among women aged $30-40,40-50,50-60$ and $>60$ years also showed significant differences from 2014 to 2018 (Table 4).

\section{TCT positive infections in women of different ages}

Characteristics of TCT test results as well as their distribution among different age categories are shown in Table 5. Among all participants, a number of 1746 (8.22\%) women were TCT positive, of whom, 858 (4.04\%), 561 (2.64\%) and 327 (1.54\%) had ASCs, LSILs and HSILs, respectively. The highest TCT positive rate was seen in women aged $40-50$ years $(8.76 \%)$, and the lowest rate was found in those women aged $30-40$ years $(7.83 \%)$. Additionally, among four cytological subtypes, HSIL detection increased significantly with age $(P<0.0001$, Table 5$)$. Moreover, among single-type and multiple-type HPV infections, the TCT positive rate was $24.77 \%(856 / 3456)$ and $34.32 \%$ (349/1017), respectively.

\section{Relationship between TCT test results and HPV subtype infections}

Among four types of cytological lesions, the HPV infection rate was $16.76 \%$ (3268/19493), 66.08\% (567/858),

Table 1 Single and multiple type infections of HPV of different ages

\begin{tabular}{lllll}
\hline Age (years) & $N$ & $\begin{array}{l}\text { HPV Positive, } \\
\mathrm{n}\left(\%^{\mathrm{a}}\right)\end{array}$ & $\begin{array}{l}\text { Single-type } \\
\text { infection, } \mathrm{n}\left(\%^{\mathrm{a}}\right)\end{array}$ & $\begin{array}{l}\text { Multiple-type } \\
\text { infection, } \mathrm{n}\left(\%{ }^{\mathrm{a}}\right)\end{array}$ \\
\hline$<30$ & 4046 & $998(24.67)$ & $679(16.78)$ & $319(7.88)$ \\
$30-40$ & 7666 & $1567(20.44)$ & $1258(16.41)$ & $309(4.03)$ \\
$40-50$ & 5014 & $949(18.93)$ & $773(15.42)$ & $176(3.51)$ \\
$50-60$ & 3157 & $679(21.51)$ & $542(17.17)$ & $137(4.34)$ \\
$>60$ & 1356 & $280(20.65)$ & $204(15.04)$ & $76(5.60)$ \\
Total & 21,239 & 4473 & 3456 & 1017 \\
\hline
\end{tabular}

HPV human papillomavirus

${ }^{a}$ Represented HPV infection rates in different age categories 
Table 2 Single and multiple type infection rates of different HPV subtypes

\begin{tabular}{llll}
\hline HPV subtype & $\begin{array}{l}\text { Positive, } \\
\mathrm{n}\left(\%^{\mathrm{a}}{ }^{2}\right.\end{array}$ & $\begin{array}{l}\text { Single-type } \\
\text { infection, } \mathrm{n}\left(\%^{\mathrm{a}}\right)\end{array}$ & $\begin{array}{c}\text { Multiple-type } \\
\text { infection, } \mathrm{n}\left(\%{ }^{\mathrm{a}}\right)\end{array}$ \\
\hline HPV16 & $942(4.44)$ & $630(2.97)$ & $312(1.47)$ \\
HPV18 & $312(1.47)$ & $185(0.87)$ & $127(0.60)$ \\
HPV31 & $264(1.24)$ & $158(0.74)$ & $106(0.50)$ \\
HPV33 & $155(0.73)$ & $83(0.39)$ & $72(0.34)$ \\
HPV35 & $205(0.97)$ & $87(0.41)$ & $118(0.56)$ \\
HPV39 & $490(2.31)$ & $217(1.02)$ & $273(1.29)$ \\
HPV45 & $86(0.40)$ & $43(0.20)$ & $43(0.20)$ \\
HPV51 & $465(2.19)$ & $266(1.25)$ & $199(0.94)$ \\
HPV52 & $986(4.64)$ & $655(3.08)$ & $331(1.56)$ \\
HPV56 & $435(2.05)$ & $253(1.19)$ & $182(0.86)$ \\
HPV58 & $909(4.28)$ & $595(2.80)$ & $314(1.48)$ \\
HPV59 & $316(1.49)$ & $184(0.87)$ & $132(0.62)$ \\
HPV68 & $258(1.21)$ & $99(0.47)$ & $159(0.75)$ \\
\hline HPV & & &
\end{tabular}

HPV human papillomavirus

${ }^{a}$ Represented HPV subtype infection rate which was calculated as the number of infected women by certain subtype of HPV was divided by the total number of participants in this study $(N=21,239)$

63.99\% (359/561), and $85.32 \%(279 / 327)$ for NILM, ASCs, LSILs and HSILs, respectively. HPV16, 52 and 58 were frequently determined in NILM, ASC and HSIL, and HPV16, 51 and 56 were commonly found in LSIL (Table 6).

\section{Discussion}

Persistent HR-HPV infection is the main cause of precancerous lesions and cervical cancer, which has been confirmed by epidemiological and biological data [23]. Active and effective detection methods for HPV are deemed important to control the development of cervical cancer. This study aimed at understanding the epidemiological characteristics of HPV infection subtypes and the relationship between the HPV testing and cytology test results in the Beijing area. Our study provided sufficient HPV genotyping data from a large Chinese female cohort in a single center. The results revealed that the total $\mathrm{HPV}$ infection rate was $21.06 \%$ in our study cohort, especially in women aged $<30$ years. HPV16, 52 and 58 were the most commonly seen subtypes. The results also showed that

Table 3 Secular trends of different HPV subtype infection rates from 2014 to 2018

\begin{tabular}{|c|c|c|c|c|c|c|}
\hline HPV subtype & $2014, n\left(\%^{a}\right)$ & $2015, n\left(\%^{a}\right)$ & $2016, n\left(\%^{a}\right)$ & $2017, \mathrm{n}\left(\%^{\mathrm{a}}\right)$ & $2018, n\left(\%^{a}\right)$ & $P$ value for trend \\
\hline HPV16 & 46 (3.91) & $194(4.23)$ & 194 (3.94) & $320(5.01)$ & $188(4.52)$ & 0.0644 \\
\hline HPV18 & $18(1.53)$ & $75(1.63)$ & $48(0.97)$ & $94(1.47)$ & $77(1.85)$ & 0.2684 \\
\hline HPV31 & $13(1.11)$ & $55(1.20)$ & $54(1.10)$ & $84(1.32)$ & $58(1.39)$ & 0.2386 \\
\hline HPV33 & $10(0.85)$ & $40(0.87)$ & $27(0.55)$ & $43(0.67)$ & $35(0.84)$ & 0.7999 \\
\hline HPV35 & $7(0.60)$ & $51(1.11)$ & $38(0.77)$ & $62(0.97)$ & 47 (1.13) & 0.3404 \\
\hline HPV39 & $20(1.70)$ & $89(1.94)$ & $92(1.87)$ & $166(2.60)$ & $123(2.96)$ & $<0.0001$ \\
\hline HPV45 & $3(0.26)$ & $15(0.33)$ & $23(0.47)$ & $26(0.41)$ & $19(0.46)$ & 0.2899 \\
\hline HPV51 & $31(2.64)$ & $83(1.81)$ & $87(1.76)$ & $149(2.33)$ & $115(2.76)$ & 0.011 \\
\hline HPV52 & $46(3.91)$ & $182(3.97)$ & $174(3.53)$ & $356(5.58)$ & $228(5.48)$ & $<0.0001$ \\
\hline HPV56 & $31(2.64)$ & $93(2.03)$ & $94(1.91)$ & $138(2.16)$ & 79 (1.90) & 0.4557 \\
\hline HPV58 & $54(4.60)$ & $179(3.90)$ & $178(3.61)$ & $306(4.79)$ & $192(4.61)$ & 0.0426 \\
\hline HPV59 & $12(1.02)$ & $71(1.55)$ & $62(1.26)$ & $100(1.57)$ & $71(1.71)$ & 0.1309 \\
\hline HPV68 & $21(1.79)$ & $63(1.37)$ & $58(1.18)$ & $55(0.86)$ & $61(1.47)$ & 0.2339 \\
\hline Total & 1175 & 4588 & 4930 & 6384 & 4162 & \\
\hline
\end{tabular}


Table 4 Secular trends of HPV and TCT infection rates of different ages from 2014 to 2018

\begin{tabular}{|c|c|c|c|c|c|c|}
\hline Age (years) & $2014, n\left(\%^{a}\right)$ & $2015, n\left(\%^{a}\right)$ & $2016, n\left(\%{ }^{a}\right)$ & $2017, \mathrm{n}\left(\%^{\mathrm{a}}\right)$ & $2018, \mathrm{n}\left(\%^{\mathrm{a}}\right)$ & $P$ value for trend \\
\hline \multicolumn{7}{|l|}{ HPV positive } \\
\hline$<30$ & 47 (18.73) & $183(20.42)$ & $208(23.27)$ & 344 (23.53) & $216(22.27)$ & 0.0002 \\
\hline $30-40$ & $91(36.25)$ & 312 (34.82) & 305 (34.12) & $473(32.35)$ & 386 (39.79) & $<0.0001$ \\
\hline $40-50$ & 48 (19.12) & $201(22.43)$ & 175 (19.57) & 339 (23.19) & 186 (19.18) & 0.0596 \\
\hline $50-60$ & $45(17.93)$ & $133(14.84)$ & $152(17.00)$ & $222(15.18)$ & 127 (13.09) & 0.879 \\
\hline$>60$ & $20(7.97)$ & $67(7.48)$ & $54(6.04)$ & $84(5.75)$ & $55(5.67)$ & 0.4306 \\
\hline Total & 251 & 896 & 894 & 1462 & 970 & - \\
\hline \multicolumn{7}{|l|}{ TCT positive } \\
\hline$<30$ & $25(18.12)$ & $69(16.67)$ & 81 (19.52) & $101(19.13)$ & 48 (19.12) & 0.0541 \\
\hline $30-40$ & 48 (34.78) & 131 (31.64) & $147(35.42)$ & $170(32.20)$ & $104(41.43)$ & 0.016 \\
\hline $40-50$ & $32(23.19)$ & $118(28.50)$ & $96(23.13)$ & $144(27.27)$ & 49 (19.52) & $<0.0001$ \\
\hline $50-60$ & $26(18.84)$ & $61(14.73)$ & $67(16.14)$ & $80(15.15)$ & $34(13.55)$ & 0.001 \\
\hline$>60$ & $7(5.07)$ & $35(8.45)$ & $24(5.78)$ & $33(6.25)$ & $16(6.37)$ & 0.0385 \\
\hline Total & 138 & 414 & 415 & 528 & 251 & - \\
\hline
\end{tabular}

HPV human papillomavirus, TCT thinprep cytology test

${ }^{a}$ Represented the percentage of HPV infection rates in different groups

the TCT positive rate was $8.22 \%$, and among four types of cytological lesions, HSIL had the highest HPV infection rate.

Previous studies have reported that the frequency of HPV infection varies geographically $[9,24,25]$. The frequency of HPV infection also varies in China because of its large population and territory, and the frequency varies from 9.9 to $31.9 \%$ in different areas in China [26-28]. In our study, $21.06 \%$ of all 21,239 cases were infected with HPV. The frequency of HPV infection reached a peak in women aged $<30$ years, gradually declined in the middle-aged groups, and then increased in women aged $>50$ years. Our results are similar to those recently published by Jiang et al [28]. However, single-type HPV infection was more frequently seen in women aged 30-40 years, and multiple-type HPV infection was more common in those aged $<30$ years. Women aged $<30$ years are sexually active and may have more than one sexual partner, so the frequency of multiple-type HPV infection is higher than in other age groups. Most HPV infections can be cleared or suppressed within 1 or 2 years in 70 $91 \%$ of cases [29]. Therefore, the higher HR-HPV prevalence among women aged $>50$ years may be associated with reduced immunity. Our data also showed that single-type infection was more common than multipletype infection. However, multiple-type infection is more dangerous than single-type infection. In this study, the TCT positive rate was higher in multiple-type than in single-type HPV infection, which is consistent with previous studies [30].

It is necessary to know the HPV genotype distribution for vaccine development. Among $13 \mathrm{HPV}$ subtypes examined in our study, HPV52, 16, and 58 had the highest prevalence in overall, single-type and multiple-type infected participants. The results showed that the most common infection was with HPV52, which was detected in $4.64 \%$ of cases. HPV16 was found in $4.44 \%$ of cases and the frequency of HPV58 was $4.28 \%$. These results were similar to previously reported data from other Chinese studies [28, 31, 32]. These studies demonstrated

Table 5 TCT positive rates of different ages

\begin{tabular}{lllllll}
\hline Age (years) & $\mathrm{N}$ & $\mathrm{NILM}, \mathrm{n}\left(\%^{\mathrm{a}}\right)$ & $\mathrm{ASC}, \mathrm{n}\left(\%^{\mathrm{a}}\right)$ & $\mathrm{LSIL}, \mathrm{n}\left(\%^{\mathrm{a}}\right)$ & $\mathrm{HSIL}, \mathrm{n}\left(\%{ }^{\mathrm{a}}\right)$ & TCT positive, $\mathrm{n}\left(\%^{\mathrm{a}}\right)$ \\
\hline$<30$ & 4046 & $3722(91.99)$ & $181(4.47)$ & $123(3.04)$ & $20(0.49)$ & $324(8.01)$ \\
$30-40$ & 7666 & $7066(92.17)$ & $300(3.91)$ & $198(2.58)$ & $102(1.33)$ & $600(7.83)$ \\
$40-50$ & 5014 & $4575(91.24)$ & $212(4.23)$ & $131(2.61)$ & $96(1.91)$ & $439(8.76)$ \\
$50-60$ & 3157 & $2889(91.51)$ & $115(3.64)$ & $80(2.53)$ & $73(2.31)$ & $268(8.49)$ \\
$>60$ & 1356 & $1241(91.52)$ & $50(3.69)$ & $29(2.14)$ & $36(2.65)$ & $115(8.48)$ \\
Total & 21,239 & 19,493 & 858 & 561 & 327 & 1746 \\
\hline
\end{tabular}

TCT thinprep cytology test, NILM negative for intraepithelial lesions or malignancy, ASC atypical squamous cells, LSIL low grade squamous intraepithelial lesion, HSIL high grade squamous intraepithelial lesion

${ }^{\text {a }}$ Represented TCT positive rates in different age categories 
Table 6 Different HPV subtype infection rates among NILM, ASC, LSIL, and HSIL, respectively

\begin{tabular}{lllll}
\hline HPV subtype & NILM (\%) & ASC (\%) & LSIL (\%) & HSIL (\%) \\
& $N=19,493$ & $N=858$ & $73(13.01)$ & $148(45.26)$ \\
\hline HPV16 & $591(3.03)$ & $130(15.15)$ & $16(2.85)$ & $16(4.89)$ \\
HPV18 & $234(1.20)$ & $46(5.36)$ & $19(3.39)$ & $16(4.89)$ \\
HPV31 & $196(1.01)$ & $33(3.85)$ & $14(2.50)$ & $12(3.67)$ \\
HPV33 & $103(0.53)$ & $26(3.03)$ & $17(3.03)$ & $11(3.36)$ \\
HPV35 & $151(0.77)$ & $26(3.03)$ & $41(7.31)$ & $13(3.98)$ \\
HPV39 & $368(1.89)$ & $68(7.93)$ & $5(0.89)$ & $3(0.92)$ \\
HPV45 & $62(0.32)$ & $16(1.86)$ & $76(13.54)$ & $14(4.28)$ \\
HPV51 & $296(1.52)$ & $79(9.21)$ & $59(10.52)$ & $32(9.79)$ \\
HPV52 & $764(3.92)$ & $131(15.27)$ & $98(17.47)$ & $8(2.45)$ \\
HPV56 & $272(1.40)$ & $57(6.64)$ & $58(10.34)$ & $57(17.43)$ \\
HPV58 & $662(3.40)$ & $132(15.38)$ & $18(3.21)$ & $6(1.83)$ \\
HPV59 & $253(1.30)$ & $39(4.55)$ & $27(4.81)$ & $5(1.53)$ \\
HPV68 & $180(0.92)$ & $46(5.36)$ &
\end{tabular}

HPV human papillomavirus, NILM negative for intraepithelial lesions or malignancy, ASC atypical squamous cells, LSIL low grade squamous intraepithelial lesion, HSIL high grade squamous intraepithelial lesion

that both HPV52 and 58 were more common among the general population in China than in developed countries.

Furthermore, because few studies have focused on the secular trends of HPV subtypes in China, we also analyzed the trends from 2014 to 2018 in our hospital. Differences were determined for subtypes HPV39, 51, 52 and 58, and HPV39 and 51 were significantly increased in recent years. Based on the results of our study and others, there was variation of HPV prevalence by geographic regions, age distribution and time. Therefore, the effectiveness of vaccination for reduction of disease burden may differ by population. Currently, the 9v HPV vaccine has been widely used clinically and it has recently been shown to prevent HPV infection among subjects with differing baseline characteristics [33]. However, vaccines including more HPV genotypes should be developed for the Beijing area, such as HPV52, 16, 58, 39 and 51, and others.

TCT is the most advanced cytological examination technique for cervical cancer globally, and its detection rate for cervical cells is near to $100 \%$ [34]. TCT represents significant progress in collecting cytological samples and preparing slides, and the technique has been certified by the US FDA and is recommended by the College of American Pathologists to replace the traditional cervical smear. In our study, a total of $1746(8.22 \%)$ women were detected as TCT positive. The highest TCT-positive rate was seen in the 40-50year age group, and the lowest in the 30-40-year age group. In addition, the reason for the higher TCTpositive rate in women aged $<30$ years may be associated with the higher frequency of HPV infection in this group. However, there is little age-specific variation in TCT-positive rate. Additionally, among four cytological subtypes, HSILs were detected significantly more with increasing age. Among single- and multiple-type HPV infection, the TCT-positive rate was significantly higher in the latter. Among the four types of cytological lesions, the HPV infection rate was $16.75,66.08,63.99$ and $85.32 \%$ for NILM, ASC, LSIL and HSIL, respectively. Our results indicated that HR-HPV infection was associated with the development of cervical lesions and the HSIL group had the highest HPV infection rate. Therefore, it was an important hint for patients with abnormal cytological results to be subjected HPV detection.

The present study included 21,239 patients between 2014 and 2018, which identified the most common HPV subtypes among women. However, there were some limitations to this study. First, this study was only carried out in a single center in the Beijing area, and more samples and multicenter data need to be detected. Second, we only detected 13 HR-HPV subtypes $(16,18,31,33,35,39,45,51,52,56,58,59$ and 68), and the other HPV subtypes such as 66 and 82 should be included in further study. Third, although we analyzed the relationship between cervical cytology and HPV genotypes, the histology was not available for correlation with HPV genotypes.

\section{Conclusions}

In summary, this retrospective study demonstrated that the three most prevalent HR-HPVs were in descending order of HPV52, 16 and 58. The secular trends from 2014 to 2018 in our data reflected that HPV39 and 51 
were increasing during recent years and that HSILs increased significantly with age. Our data provide valuable information for HPV-based screening and prevention strategies for women in Beijing area. Because of differences in HPV subtypes between China and western countries, next-generation HPV vaccines including HPV52, 16, 58, 39 and 51 should be considered in the near future.

\section{Abbreviations}

ASCs: Atypical squamous cells; HPV: Human papillomavirus; HR-HPV: High-risk HPV; HSILs: High-grade squamous intraepithelial lesions; LSILs: Low-grade squamous intraepithelial lesions; TCT: ThinPrep cytological test

\section{Acknowledgements}

Not applicable.

\section{Authors' contributions}

LM (Liang Ma) and YTC conceived and designed the study, having full access to all of the data in the study and taking responsibility for the content of the manuscript. JPL analyzed the data, took responsibility for the accuracy of the data analysis and wrote the first draft of the manuscript. LM (Li Ma), XC, NW, HY, QL, and YY contributed to the interpretation of the data and clinical inputs. All authors were involved in the revision of the manuscript for important intellectual content and approved the final version to be published.

\section{Funding}

None.

\section{Availability of data and materials}

The datasets used and/or analysed during the current study are available from the corresponding author on reasonable request.

\section{Ethics approval and consent to participate}

Written informed consent was obtained from all the patients prior to their enrollment in the study. The study design adhered to the principles of the Declaration of Helsinki and was approved by the ethics committee of ChinaJapan Friendship Hospital.

\section{Consent for publication}

Not applicable.

\section{Competing interests}

The authors declare that they have no competing interests.

\section{Author details}

${ }^{1}$ Clinical Laboratory, China-Japan Friendship Hospital, Beijing, People's Republic of China. ${ }^{2}$ Data and Project Management Unit, Institute of Clinical Medical Sciences, China-Japan Friendship Hospital, Beijing, China. ${ }^{3}$ Institute of Respiratory Medicine, Chinese Academy of Medical Sciences, Beijing, China. ${ }^{4}$ National Clinical Research Center for Respiratory Diseases, Beijing, China. ${ }^{5}$ Department of Gynaecology \& Obstetrics, China-Japan Friendship Hospital, Beijing, China. ${ }^{6}$ Department of Blood Transfusion, China-Japan Friendship Hospital, Beijing, China.

Received: 16 March 2019 Accepted: 24 July 2019

Published online: 29 July 2019

\section{References}

1. Bray F, Ferlay J, Soerjomataram I, Siegel RL, Torre LA, Jemal A. Global cancer statistics 2018: GLOBOCAN estimates of incidence and mortality worldwide for 36 cancers in 185 countries. CA Cancer J Clin. 2018;68(6):394-424.

2. Ferlay J, Soerjomataram I, Dikshit R, Eser S, Mathers C, Rebelo M, Parkin DM, Forman D, Bray F. Cancer incidence and mortality worldwide: sources, methods and major patterns in GLOBOCAN 2012. Int J Cancer. 2015;136(5):E359-86

3. Chen W, Zheng R, Baade PD, Zhang S, Zeng H, Bray F, Jemal A, Yu XQ, He J. Cancer statistics in China, 2015. CA Cancer J Clin. 2016;66(2):115-32.
4. Walboomers JM, Jacobs MV, Manos MM, Bosch FX, Kummer JA, Shah KV, Snijders PJ, Peto J, Meijer CJ, Muñoz N. Human papillomavirus is a necessary cause of invasive cervical cancer worldwide. J Pathol. 1999;189(1):12-9.

5. Baseman JG, Koutsky LA. The epidemiology of human papillomavirus infections. J Clin Virol. 2005;32(Suppl 1):S16-24.

6. Woodman CB, Collins SI, Young LS. The natural history of cervical HPV infection: unresolved issues. Nat Rev Cancer. 2007;7(1):11-22.

7. de Martel C, Ferlay J, Franceschi S, Vignat J, Bray F, Forman D, Plummer M Global burden of cancers attributable to infections in 2008: a review and synthetic analysis. Lancet Oncol. 2012;13(6):607-15.

8. Crosbie EJ, Einstein MH, Franceschi S, HC K. Human papillomavirus and cervical cancer. Lancet. 2013;382(9895):889-99.

9. Bruni L, Diaz M, Castellsagué X, Ferrer E, Bosch FX, dS S. Cervical human papillomavirus prevalence in 5 continents: meta-analysis of 1 million women with normal cytological findings. J Infect Dis. 2010;202(12):1789-99.

10. Zhao FH, Lewkowitz AK, Hu SY, Chen F, Li LY, Zhang QM, Wu RF, Li CQ, Wei $\mathrm{LH}, \mathrm{Xu} \mathrm{AD}$, et al. Prevalence of human papillomavirus and cervical intraepithelial neoplasia in China: a pooled analysis of 17 population-based studies. Int J Cancer. 2012;131(12):2929-38.

11. Ronco G, Dillner J, Elfström KM, Tunesi S, Snijders PJ, Arbyn M, Kitchener H, Segnan N, Gilham C, Giorgi-Rossi P, et al. Efficacy of HPV-based screening for prevention of invasive cervical cancer: follow-up of four European randomised controlled trials. Lancet. 2014:383(9916):524-32.

12. Cuzick J, Cadman L, Mesher D, Austin J, Ashdown-Barr L, Ho L, Terry G, Liddle $\mathrm{S}$, Wright $\mathrm{C}$, Lyons $\mathrm{D}$, et al. Comparing the performance of six human papillomavirus tests in a screening population. Br J Cancer. 2013;108(4):908-13.

13. Castle PE, de Sanjosé S, Qiao YL, Belinson JL, Lazcano-Ponce E, Kinney W. Introduction of human papillomavirus DNA screening in the world: 15 years of experience. Vaccine. 2012;30(Suppl 5):F117-22.

14. Pileggi C, Flotta D, Bianco A, Nobile CG, Pavia M. Is HPV DNA testing specificity comparable to that of cytological testing in primary cervical cancer screening? Results of a meta-analysis of randomized controlled trials. Int J Cancer. 2014;135(1):166-77.

15. Costa S, Sideri M, Negri G, Venturoli S, Santini D, Casadio C, Sandri MT, Bucchi $L$. The predictive value of human papillomavirus testing for the outcome of patients conservatively treated for stage IA squamous cell cervical carcinoma. J Clin Virol. 2015;70:53-7.

16. Belinson JL, Pretorius RG, Enerson C, Garcia F, Cruz EP, Belinson SE, Yeverino García E, Brainard J. The Mexican cervical Cancer screening trial: selfsampling for human papillomavirus with unaided visual inspection as a secondary screen. Int J Gynecol Cancer. 2009;19(1):27-32.

17. Zhao C, Li Z, Nayar R, Levi AW, Winkler BA, Moriarty AT, Barkan GA, Rao J, Miller F, Fan F, et al. Prior high-risk human papillomavirus testing and Papanicolaou test results of 70 invasive cervical carcinomas diagnosed in 2012: results of a retrospective multicenter study. Arch Pathol Lab Med. 2015;139(2):184-8.

18. Saslow D, Solomon D, Lawson HW, Killackey M, Kulasingam SL, Cain J, Garcia FA, Moriarty AT, Waxman AG, Wilbur DC, et al. American Cancer Society, American Society for Colposcopy and Cervical Pathology, and American Society for Clinical Pathology screening guidelines for the prevention and early detection of cervical cancer. CA Cancer J Clin. 2012; 62(3):147-72.

19. Kulasingam SL, Hughes JP, Kiviat NB, Mao C, Weiss NS, Kuypers JM, Koutsky LA. Evaluation of human papillomavirus testing in primary screening for cervical abnormalities: comparison of sensitivity, specificity, and frequency of referral. JAMA. 2002;288(14):1749-57.

20. Rijkaart DC, Berkhof J, Rozendaal L, van Kemenade FJ, Bulkmans NW, Heideman DA, Kenter GG, Cuzick J, Snijders PJ, Meijer CJ. Human papillomavirus testing for the detection of high-grade cervical intraepithelia neoplasia and cancer: final results of the POBASCAM randomised controlled trial. Lancet Oncol. 2012;13(1):78-88.

21. Wright TC, Stoler MH, Behrens CM, Sharma A, Zhang G, Wright TL. Primary cervical cancer screening with human papillomavirus: end of study results from the ATHENA study using HPV as the first-line screening test. Gynecol Oncol. 2015;136(2):189-97.

22. Nayar R, Wilbur DC. The Bethesda system for reporting cervical cytology: a historical perspective. Acta Cytol. 2017;61(4-5):359-72.

23. de Sanjose S, Quint WG, Alemany L, Geraets DT, Klaustermeier JE, Lloveras B, Tous S, Felix A, Bravo LE, Shin HR, et al. Human papillomavirus genotype attribution in invasive cervical cancer: a retrospective cross-sectional worldwide study. Lancet Oncol. 2010;11(11):1048-56. 
24. Zhao FH, Lin MJ, Chen F, Hu SY, Zhang R, Belinson JL, Sellors JW, Franceschi $\mathrm{S}$, Qiao YL, Castle PE, et al. Performance of high-risk human papillomavirus DNA testing as a primary screen for cervical cancer: a pooled analysis of individual patient data from 17 population-based studies from China. Lancet Oncol. 2010;11(12):1160-71.

25. Forman D, de Martel C, Lacey CJ, Soerjomataram I, Lortet-Tieulent J, Bruni L, Vignat J, Ferlay J, Bray F, Plummer M, et al. Global burden of human papillomavirus and related diseases. Vaccine. 2012;30(Suppl 5):F12-23.

26. Zeng Z, Austin RM, He X, Chen X, Guo X, Zheng B, Wu S, Yang H, Zhao C. Prevalence of high-risk human papillomavirus infection in China: analysis of 671,163 human papillomavirus test results from China's largest college of American pathologists-certified laboratory. Am J Clin Pathol. 2016;145(5):622-5.

27. Zeng Z, Yang H, Li Z, He X, Griffith CC, Chen X, Guo X, Zheng B, Wu S, Zhao C. Prevalence and genotype distribution of HPV infection in China: analysis of 51,345 HPV genotyping results from China's largest CAP certified laboratory. J Cancer. 2016;7(9):1037-43.

28. Jiang L, Tian X, Peng D, Zhang L, Xie F, Bi C, Wang R, Wang J, Qi D. HPV prevalence and genotype distribution among women in Shandong Province, China: Analysis of 94,489 HPV genotyping results from Shandong's largest independent pathology laboratory. PLoS One. 2019;14(1):e0210311.

29. Schiffman M, Castle PE, Jeronimo J, Rodriguez AC. S. W: Human papillomavirus and cervical cancer. Lancet. 2007;370(9590):890-907.

30. Srodon M, Parry Dilworth H, Ronnett BM. Atypical squamous cells, cannot exclude high-grade squamous intraepithelial lesion: diagnostic performance, human papillomavirus testing, and follow-up results. Cancer. 2006;108(1):32-8.

31. Bi Q, Zhang L, Zhao Z, Mu X, Zhang M, Wang P. Human papillomavirus prevalence and genotypes distribution among female outpatients in Qingdao, East China. J Med Virol. 2015;87(12):2114-21.

32. Zhu X, Liu H, Wu H, Liu W, Yin L, Sun X. Carcinogenic ability quantification of human papilloma virus subtypes in eastern China. J Med Virol. 2015;87(12):2106-13.

33. Petersen LK, Restrepo J, Jr Moreira ED, Iversen OE, Pitisuttithum P, Van Damme $P$, Joura EA, Olsson SE, Ferris $D$, Block $S$, et al. Impact of baseline covariates on the immunogenicity of the 9-valent HPV vaccine - a combined analysis of five phase III clinical trials. Papillomavirus Res. 2017;3:105-15.

34. Xue Y, An R, Zhang D, Zhao J, Wang X, Yang L, He D. Detection of survivin expression in cervical cancer cells using molecular beacon imaging: new strategy for the diagnosis of cervical cancer. Eur J Obstet Gynecol Reprod Biol. 2011;159(1):204-8.

\section{Publisher's Note}

Springer Nature remains neutral with regard to jurisdictional claims in published maps and institutional affiliations.

Ready to submit your research? Choose BMC and benefit from:

- fast, convenient online submission

- thorough peer review by experienced researchers in your field

- rapid publication on acceptance

- support for research data, including large and complex data types

- gold Open Access which fosters wider collaboration and increased citations

- maximum visibility for your research: over $100 \mathrm{M}$ website views per year

At $\mathrm{BMC}$, research is always in progress.

Learn more biomedcentral.com/submissions 